\title{
Effect of Trapezoidal-Shaped Well on Efficiency Droop in InGaN-Based Double-Heterostructure Light-Emitting Diodes
}

\author{
Ray-Ming Lin, ${ }^{1}$ Mu-Jen Lai, ${ }^{1}$ Liann-Be Chang, ${ }^{1}$ Chou-Hsiung Huang, ${ }^{1}$ and Chang-Ho Chen ${ }^{2}$ \\ ${ }^{1}$ Graduate Institute of Electronic Engineering and Green Technology Research Center, Chang Gung University, Taoyuan 333, Taiwan \\ ${ }^{2}$ MOME, Business Development Group, LED Division, Taoyuan 333, Taiwan
}

Correspondence should be addressed to Ray-Ming Lin, rmlin@mail.cgu.edu.tw

Received 26 July 2011; Revised 8 November 2011; Accepted 16 November 2011

Academic Editor: Carmen Hidalgo

Copyright ( 2012 Ray-Ming Lin et al. This is an open access article distributed under the Creative Commons Attribution License, which permits unrestricted use, distribution, and reproduction in any medium, provided the original work is properly cited.

\begin{abstract}
We investigated the effects of different well shapes on the external quantum efficiency (EQE) and the efficiency droop in wide-well InGaN/GaN double-heterostructure light-emitting diodes. For forward current densities in the measurement range of greater than $135 \mathrm{~A} / \mathrm{cm}^{2}$, the device featuring a trapezoidal well exhibited improved EQEs and alleviative efficiency droop, relative to those of the device featuring a rectangular well. The decreased Auger loss has been proposed as the main reason for the greater maximum efficiency that occurred at high current density $\left(>50 \mathrm{~A} / \mathrm{cm}^{2}\right)$. For the devices incorporating trapezoidal and rectangular wells, the EQEs at $200 \mathrm{~A} / \mathrm{cm}^{2}$ decreased by 14 and $40 \%$, respectively, from their maximum values, resulting in the EQE at a current density of $200 \mathrm{~A} / \mathrm{cm}^{2}$ of the device featuring a trapezoidal well being $17.5 \%$ greater than that featuring a rectangular well. These results suggest that, in addition to the decreased Auger loss, the alleviation in efficiency droop at higher current densities might be due to higher internal quantum efficiency resulted from the improved carrier injection efficiency of the trapezoidal well.
\end{abstract}

\section{Introduction}

Research and development related to InGaN-based lightemitting diodes (LEDs) is currently of very high interest because of their applications as replacements for conventional lighting devices, including incandescent light bulbs, fluorescent lamps, and automotive head lamps. Many applications in the solid state general lighting industry require high light-output power, which can be achieved using a higher input current. Typical InGaN-based LEDs suffer, however, from a decrease in external quantum efficiency (EQE) at high injection current densities; this well-established phenomenon is known as "efficiency droop." To ensure that InGaN-based LEDs will be suitable for application in high-power solid state general lighting, it is imperative to overcome the efficiency droop phenomenon. Experimental and theoretical studies have suggested several different mechanisms to explain the phenomenon of efficiency droop, including carrier delocalization from In-rich clusters [1], junction heat [2], decreased injection efficiency [3], Auger loss $[4,5]$, polarization mismatches $[6,7]$, current rollover [8-10], defect-related tunneling [11], and interface states
[12]. Although the Auger loss mechanism has been proposed to cause the efficiency droop in experiments using InGaN/ $\mathrm{GaN}$ double-heterostructure (DH) active regions $[4,5]$, it is expected to be very small in semiconductors having wide band gaps, as has been verified using many-body models [13]. Nevertheless, according to the concept of carrier leakage from multiple quantum wells (MQWs), caused by the polarization field, the efficiency droop can be minimized when using AlInGaN, AlGaN, AlInN barriers or InGaN/GaN multilayer barriers [7, 14-16]. In addition, the efficiency droop can be improved by employing a trapezoidal well (TZW) in the MQWs active region to replace the conventional rectangular well [17]. The EQEs of these two differently shaped wells cross each other at $5 \mathrm{~A} / \mathrm{cm}^{2}$, which is a very low value when compared with previous results. It was suggested that the use of the trapezoidal well improved the internal quantum efficiency, with enhanced overlap of the electron and hole wave functions, due to a lower piezoelectric field at high current densities.

At present, most studies on the efficiency droops of LEDs have been made using InGaN/GaN MQWs as the active region; only a few examinations have been made into the 
mechanisms in InGaN-based DH structures. In this study, we investigated the impacts of trapezoidal and conventional rectangular wells on the efficiency droop phenomena when using a wide-well InGaN/GaN DH structure as the active region.

\section{Experimental Procedure}

The LED samples used in this study were grown on c-plane (0001) sapphire substrates through atmospheric-pressure metal, organic chemical vapor deposition (AP-MOCVD) in a Taiyo Nippon Sanso reactor system. Trimethylgallium (TMGa), trimethylindium (TMIn), trimethylaluminum (TMAl), and ammonia $\left(\mathrm{NH}_{3}\right)$ were used as source materials for $\mathrm{Ga}$, In, $\mathrm{Al}$, and $\mathrm{N}$ atoms, respectively. Silane $\left(\mathrm{SiH}_{4}\right)$ and biscyclopentadienyl magnesium $\left(\mathrm{CP}_{2} \mathrm{Mg}\right)$ were used as the $\mathrm{n}$ - and p-type doping sources, respectively. To avoid higher strain-induced piezoelectric fields in the LED structures, an active region having a lower In composition and the EBL of superlattice structure were used; prior to this growth, several calibration runs were carried out for the confirmation of the stoichiometrical ratio in the epilayers, and the estimated composition was determined by using high resolution $\mathrm{X}$-ray diffraction for certifying the exact compositions. A $25 \mathrm{~nm}$ thick GaN nucleation layer was grown at $520^{\circ} \mathrm{C}$, followed by a $1.3 \mu \mathrm{m}$ thick undoped $\mathrm{GaN}$ layer at $1130^{\circ} \mathrm{C}$. Tenperiod n-type $\mathrm{Al}_{0.2} \mathrm{Ga}_{0.8} \mathrm{~N}(2.4 \mathrm{~nm}) / \mathrm{GaN}$ (2.8 nm) structures were deposited and then a $3 \mu \mathrm{m}$ thick Si-doped n-type $\mathrm{GaN}$ layer was deposited at $1130^{\circ} \mathrm{C}$. An active region was grown on the Si-doped n-type $\mathrm{GaN}$ layer at $805^{\circ} \mathrm{C}$ and then 10-period p-type $\mathrm{Al}_{0.1} \mathrm{Ga}_{0.9} \mathrm{~N}(4 \mathrm{~nm}) / \mathrm{GaN}(4 \mathrm{~nm})$ superlattice structures were deposited as the EBL over the active region. Finally, a $100 \mathrm{~nm}$ thick heavily doped p-type $\mathrm{GaN}$ contact layer was deposited upon the EBL at $1030^{\circ} \mathrm{C}$. Two types of $\mathrm{DH}$ active regions were grown, denoted herein as samples A and B. For a valid comparison, the thickness of the InGaN active region was selected to be $10 \mathrm{~nm}$. Sample A (Figure 1(a)) had a DH active region consisting of $\mathrm{GaN}(2 \mathrm{~nm}) / \mathrm{In}_{x} \mathrm{Ga}_{1-x} \mathrm{~N}$ (with $x$ ramping from 0 to 0.08$)(1 \mathrm{~nm}) / \mathrm{In}_{0.08} \mathrm{Ga}_{0.92} \mathrm{~N}(8 \mathrm{~nm}) / \mathrm{In}_{x} \mathrm{Ga}_{1-x} \mathrm{~N}$ (with $x$ ramping from 0.08 to 0$)(1 \mathrm{~nm}) / \mathrm{GaN}(2 \mathrm{~nm})$. For sample $\mathrm{B}$ (Figure $1(\mathrm{~b})$ ), the $\mathrm{DH}$ active region consisted of $\mathrm{GaN}$ $(2 \mathrm{~nm}) / \mathrm{In}_{0.08} \mathrm{Ga}_{0.92} \mathrm{~N}(10 \mathrm{~nm}) / \mathrm{GaN}(2 \mathrm{~nm})$. After growing the LED structures, a chip $\left(1 \times 1 \mathrm{~mm}^{2}\right)$ was fabricated through the standard process of lateral electrodes with interposed fingers. The fabricated chips were bonded on the ceramic lead frames of a surface mount-type and encapsulated with epoxy resin. Electroluminescence (EL) was measured using a Light Ports integrating sphere at room temperature in the dc pulse operation mode (pulse width: $100 \mu \mathrm{s}$; duty cycle: $1 \%$ ) to eliminate the self-heating effect.

\section{Results and Discussion}

Figure 2(a) displays the light output power of samples A and $B$ plotted with respect to the forward current density. The light output powers of both samples underwent sublinear increases upon increasing the current density. The light
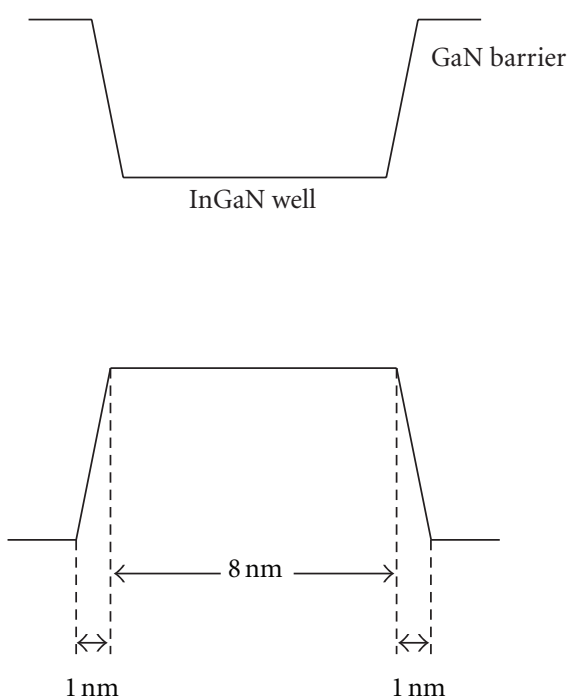

(a)
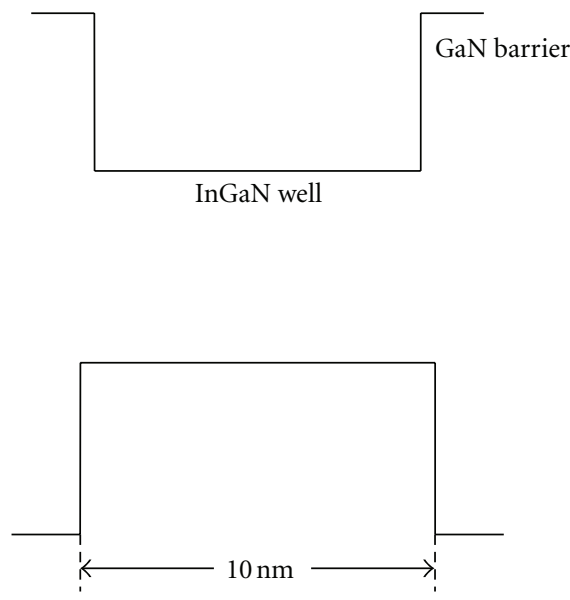

(b)

Figure 1: Schematic band diagrams for (a) sample A (trapezoidal well) and (b) sample B (rectangular well).

output power of sample B was greater than that of sample A in the measurement range from 5 to $135 \mathrm{~A} / \mathrm{cm}^{2}$, whereas the light output power of sample A surpassed that of sample B at current densities of greater than $135 \mathrm{~A} / \mathrm{cm}^{2}$. At a current density of $200 \mathrm{~A} / \mathrm{cm}^{2}$, the output power of sample A was $17 \%$ greater than that of sample B. Figure $2(\mathrm{~b})$ presents the normalized EQEs of samples A and B plotted with respect to the forward current density. The normalized EQE of sample A increased monotonically from 5 to $100 \mathrm{~A} / \mathrm{cm}^{2}$ and then decreased slightly up to $200 \mathrm{~A} / \mathrm{cm}^{2}$. The normalized peak efficiency was $82 \%$, decreasing to $70.5 \%$ at $200 \mathrm{~A} / \mathrm{cm}^{2}$. For sample $\mathrm{B}$, the normalized EQE reached a maximum $(100 \%)$ at $65 \mathrm{~A} / \mathrm{cm}^{2}$ and then decreased monotonically to $60 \%$ at a current density of $200 \mathrm{~A} / \mathrm{cm}^{2}$. Thus, the EQEs of samples $\mathrm{A}$ and $\mathrm{B}$ decreased from their peak values by 14 and $40 \%$, respectively. Notably, however, sample A featuring a trapezoidal well, which exhibited an improved EQE and a significantly alleviated efficiency droop, relative to those of sample $\mathrm{B}$, at forward current densities greater than $135 \mathrm{~A} / \mathrm{cm}^{2}$. 


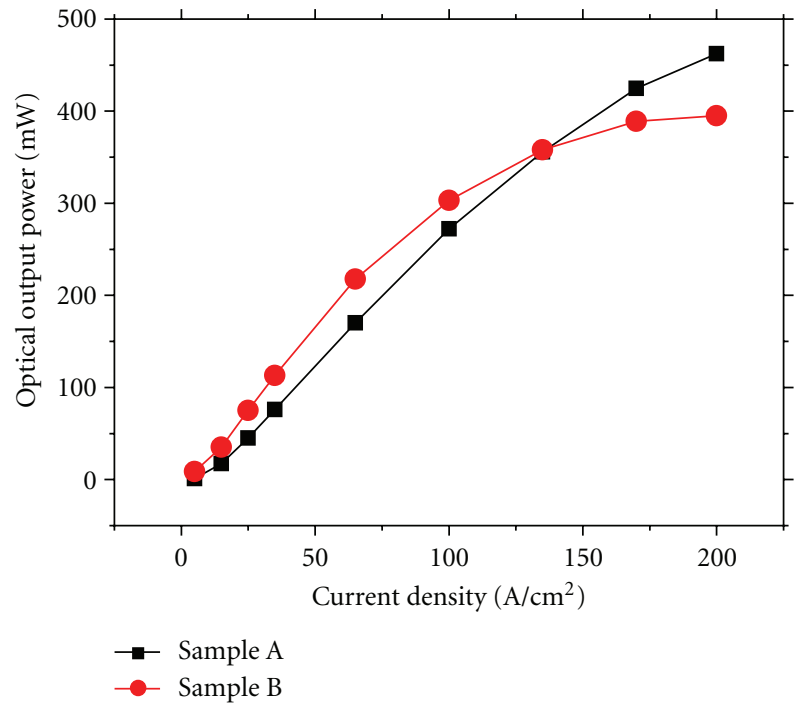

(a)

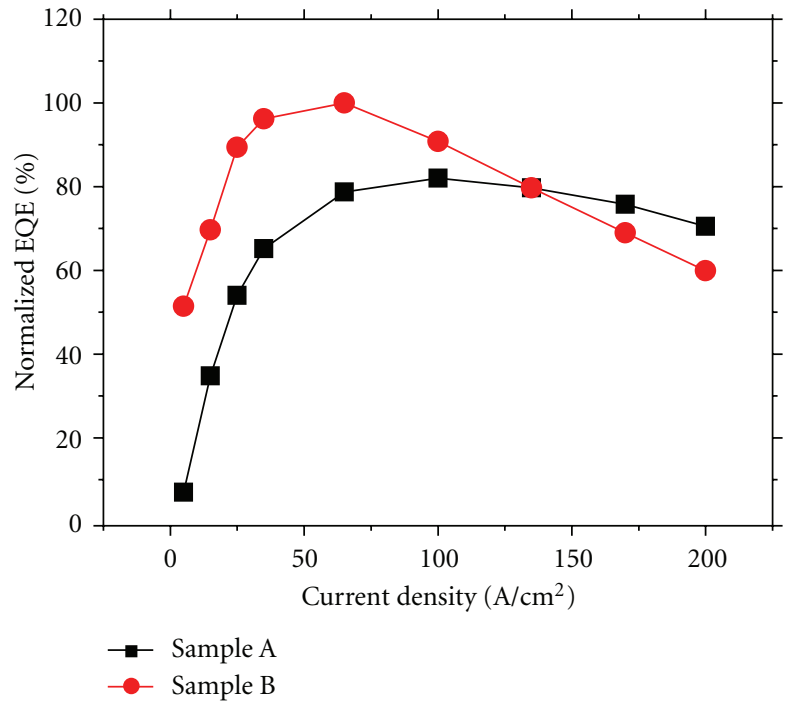

(b)

FIGURE 2: (a) Light output power and (b) normalized EQE of LED samples A and B, plotted with respect to the forward current density.

To delineate the efficiency droop phenomena occurring in this study, we explored the mechanisms other than decreased Auger loss resulted from a thicker InGaN active region. Although decreased Auger loss might have been mainly responsible for the improvement in maximum efficiency that occurred at a high current density $\left(>50 \mathrm{~A} / \mathrm{cm}^{2}\right)$ in both samples A and B, the relative efficiency droop of sample $B$ was larger than that of sample $A$ from the maximum value at $65 \mathrm{~A} / \mathrm{cm}^{2}$ up to $200 \mathrm{~A} / \mathrm{cm}^{2}$. Because the thickness of a trapezoidal well in the active region of sample A was $8 \mathrm{~nm}$, narrower than that $(10 \mathrm{~nm})$ of a rectangular well in sample $\mathrm{B}$, the Auger loss mechanism alone does not satisfactorily explain the difference in efficiency droop between samples $\mathrm{A}$ and B. However, according to calculated results for InGaN/GaN MQW LEDs, the separation of electron and hole wave functions in the active region is decreased significantly in trapezoidal wells [17]. Therefore, the alleviation in the efficiency droop might also be attributable to higher internal quantum efficiencies at higher current densities, that is due to the increased carrier injection efficiency at the graded interfaces in the active region of sample A.

Figures 3(a) and 3(b) present the EL spectra with the forward current density for samples A and B. Samples A and $B$ exhibited blue shifts of their EL peak wavelengths when the forward current density was less than $35 \mathrm{~A} / \mathrm{cm}^{2}$ and redshifts when the current density was greater than $35 \mathrm{~A} / \mathrm{cm}^{2}$. This blue-shift phenomenon was presumably caused by a decrease in the quantum-confined Stark effect (QCSE) and the band filling effect induced by the applied bias. It has been suggested that the red-shift phenomenon is caused by band gap renormalization at a lower current density for nearUV InGaN-based MQWs LEDs [18] and by a self-heating effect at higher current density [19]. Notably, however, the effect of the current density on the shift of the EL peak wavelength is inconsistent with the tendency of the peak EQE in Figure 2(b). Therefore, we suggest that the improvement of the peak EQE was not partially due to the reduction of the piezoelectric field and the renormalization of the band gap. Moreover, Figure 4 reveals that the forward voltage of sample A was slightly greater than that of sample B. This result violates the notion that using the trapezoidal well would induce a higher barrier to carrier flow than that obtained with a rectangular well; it is inconsistent with previous reports of an InGaN/GaN MQWs LED [17] and the use of an AlInGaN barrier to minimize the polarization mismatch [7]. Thus, we suggest that using the TZW structure would improve the carrier injection efficiency that not only increases the recombination rate, but also mitigates the piling up of unrecombined carriers, that could in turn increases the Auger effect. In other words, the joint effort of reduced Auger loss and improved carrier injection efficiency of structure featuring the active region with the smooth interface should affect the efficiency droop at higher current densities.

\section{Conclusions}

We have investigated efficiency droop phenomena in widewell InGaN-based DH LEDs featuring trapezoidal and rectangular active regions. For the sample with trapezoidal well, it exhibited improved EQE and the efficiency droop was alleviated significantly, relative to those for the rectangular well, for current densities in the measurement range of greater than $135 \mathrm{~A} / \mathrm{cm}^{2}$. It had been suggested that decreased Auger loss might be mainly responsible for the improvement in maximum efficiency that occurred at a high current density $\left(>50 \mathrm{~A} / \mathrm{cm}^{2}\right)$. The EQEs of the trapezoidal and rectangular wells decreased from their maximum values by 14 and 40\%, respectively, upon increasing the current density to $200 \mathrm{~A} / \mathrm{cm}^{2}$. Nevertheless, the relative maximum EQEs at 


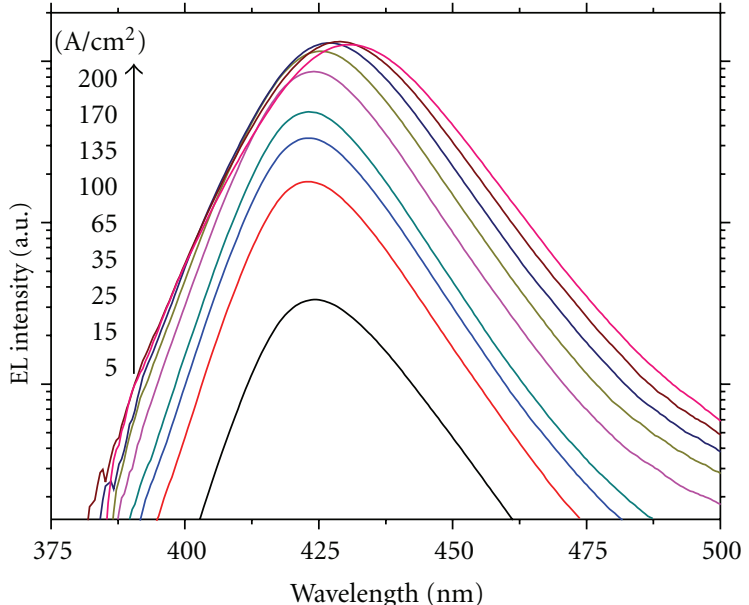

(a)

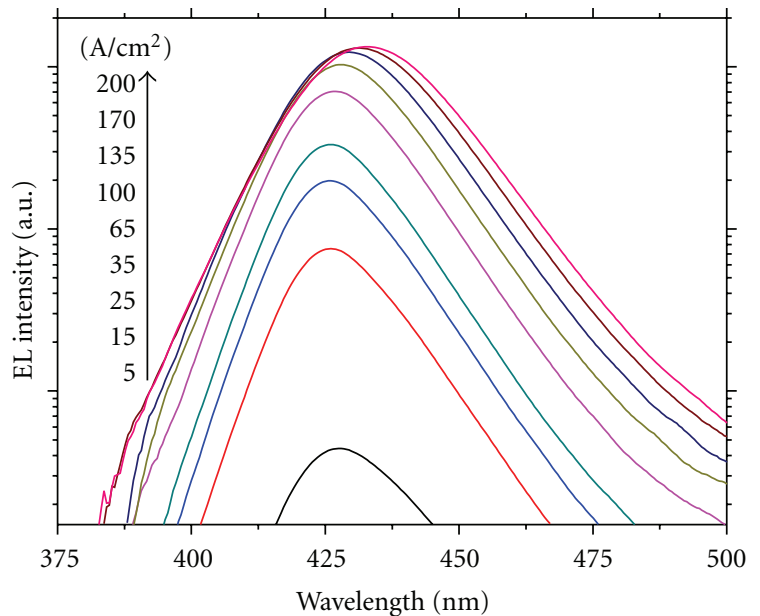

(b)

Figure 3: EL spectra of (a) sample A and (b) sample B at various forward current densities.

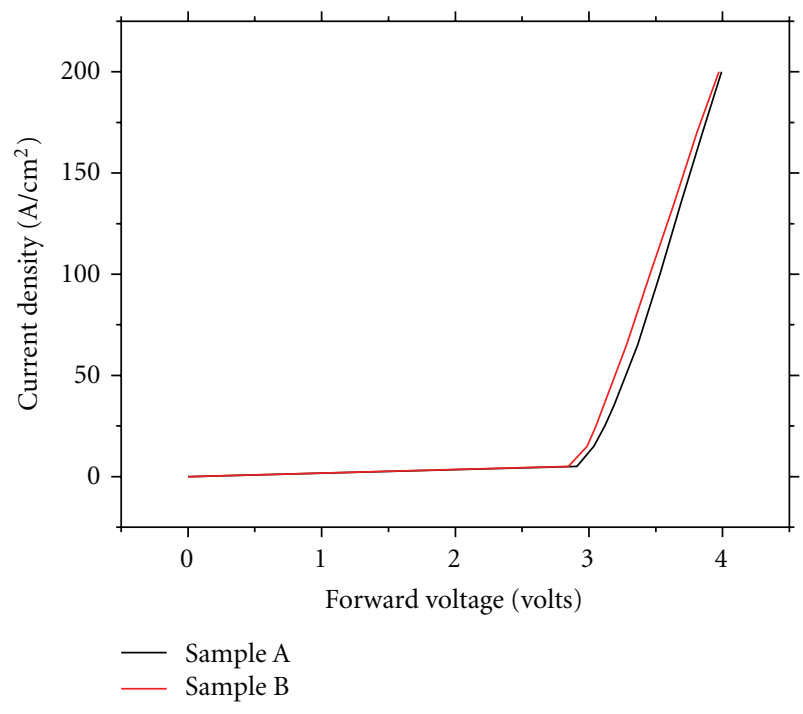

Figure 4: Current forward voltage curves of samples A and B.

a current density of $200 \mathrm{~A} / \mathrm{cm}^{2}$ for the $\mathrm{DH}$ active regions having trapezoidal and rectangular wells were 70.5 and $60 \%$, respectively. In other words, the EQE for the device featuring a trapezoidal well was $17.5 \%$ greater than that featuring a rectangular well at a current density of $200 \mathrm{~A} / \mathrm{cm}^{2}$. We propose that, in addition to the decreased Auger loss, the alleviation in efficiency droop when using trapezoidal-well InGaN-based DH LEDs, at higher current density, might also be attributed to the higher internal quantum efficiency and/or the enhancement of carrier injection efficiency that in turn alleviates the carrier accumulation, wherein, lowers the Auger loss; in summary, both the reduction of the Auger effect and the improvement of the carrier injection efficiency should be as important for the effort of entirely solving the efficiency drooping problem of nitride LED at high current operation.

\section{Acknowledgments}

This study was supported by the National Science Council of Taiwan, Taiwan (project no. NSC98-2221-E-182-058). The authors thank Intematix Technology Center Corporation for their support with the EL measurements.

\section{References}

[1] A. Y. Kim, W. Götz, D. A. Steigerwald et al., "Performance of high-power AlInGaN light emitting diodes," Physica Status Solidi A, vol. 188, no. 1, pp. 15-21, 2001.

[2] A. A. Efremov, N. I. Bochkareva, R. I. Gorbunov et al., "Effect of the joule heating on the quantum efficiency and choice of thermal conditions for high-power blue InGaN/GaN LEDs," Semiconductors, vol. 40, no. 5, pp. 605-610, 2006.

[3] I. V. Rozhansky and D. A. Zakheim, "Analysis of processes limiting quantum efficiency of AlGaInN LEDs at high pumping," Physica Status Solidi A, vol. 204, no. 1, pp. 227-230, 2007.

[4] Y. C. Shen, G. O. Mueller, S. Watanabe, N. F. Gardner, A. Munkholm, and M. R. Krames, "Auger recombination in InGaN measured by photoluminescence," Applied Physics Letters, vol. 91, no. 14, p. 141101, 2007.

[5] N. F. Gardner, G. O. Müller, Y. C. Shen et al., "Blue-emitting InGaN-GaN double-heterostructure light-emitting diodes reaching maximum quantum efficiency above $200 \mathrm{~A} \mathrm{~cm} 2$," Applied Physics Letters, vol. 91, no. 24, Article ID 243506, 2007.

[6] M. H. Kim, M. F. Schubert, Q. Dai et al., "Origin of efficiency droop in GaN-based light-emitting diodes," Applied Physics Letters, vol. 91, no. 18, Article ID 183507, 2007.

[7] M. F. Schubert, J. Xu, J. K. Kim et al., "Polarization-matched GaInNAlGaInN multi-quantum-well light-emitting diodes with reduced efficiency droop," Applied Physics Letters, vol. 93, no. 4, Article ID 041102, 2008.

[8] I. A. Pope, P. M. Smowton, P. Blood, J. D. Thomson, M. J. Kappers, and C. J. Humphreys, "Carrier leakage in InGaN quantum well light-emitting diodes emitting at $480 \mathrm{~nm}$," Applied Physics Letters, vol. 82, no. 17, pp. 2755-2757, 2003. 
[9] B. Monemar and B. E. Sernelius, "Defect related issues in the "current roll-off" in InGaN based light emitting diodes," Applied Physics Letters, vol. 91, no. 18, Article ID 181103, 2007.

[10] X. Ni, Q. Fan, R. Shimada, Ü. Özgür, and H. Morkoç, "Reduction of efficiency droop in InGaN light emitting diodes by coupled quantum wells," Applied Physics Letters, vol. 93, no. 17, Article ID 171113, 2008.

[11] N. I. Bochkareva, V. V. Voronenkov, R. I. Gorbunov et al., "Defect-related tunneling mechanism of efficiency droop in III-nitride light-emitting diodes," Applied Physics Letters, vol. 96, no. 13, Article ID 133502, 2010.

[12] M. J. Lai, L. B. Chang, R. M. Lin, and C. S. Huang, "Improvement of external quantum efficiency in InGaN-based doubleheterostructure light-emitting diodes," Applied Physics Express, vol. 3, no. 7, Article ID 072102, 2010.

[13] J. Hader, J. V. Moloney, B. Pasenow et al., "On the importance of radiative and Auger losses in GaN-based quantum wells," Applied Physics Letters, vol. 92, no. 26, Article ID 261103, 2008.

[14] J. Y. Chang, M. C. Tsai, and Y. K. Kuo, "Advantages of blue InGaN light-emitting diodes with AlGaN barriers," Optics Letters, vol. 35, no. 9, pp. 1368-1370, 2010.

[15] S. Choi, H. J. Kim, S. S. Kim et al., "Improvement of peak quantum efficiency and efficiency droop in III-nitride visible light-emitting diodes with an InAlN electron-blocking layer," Applied Physics Letters, vol. 96, no. 22, Article ID 221105, 2010.

[16] H. J. Chung, R. J. Choi, M. H. Kim et al., "Improved performance of GaN-based blue light emitting diodes with InGaN/ GaN multilayer barriers," Applied Physics Letters, vol. 95, no. 24, Article ID 241109, 2009.

[17] S. H. Han, D. Y. Lee, H. W. Shim et al., "Improvement of efficiency droop in InGaN/GaN multiple quantum well lightemitting diodes with trapezoidal wells," Journal of Physics D, vol. 43, no. 35, Article ID 354004, 2010.

[18] A. Knauer, H. Wenzel, T. Kolbe et al., "Effect of the barrier composition on the polarization fields in near UV InGaN light emitting diodes," Applied Physics Letters, vol. 92, no. 19, Article ID 191912, 2008.

[19] J. Cho, C. Sone, Y. Park, and E. Yoon, "Measuring the junction temperature of III-nitride light emitting diodes using electroluminescence shift," Physica Status Solidi A, vol. 202, no. 9, pp. 1869-1873, 2005. 


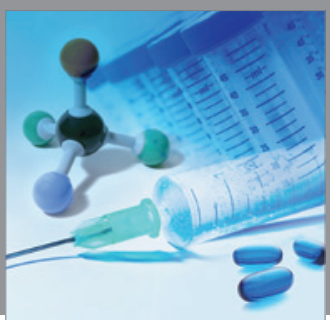

International Journal of

Medicinal Chemistry

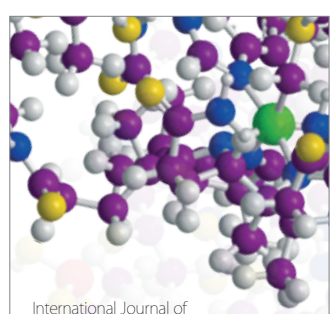

Carbohydrate Chemistry

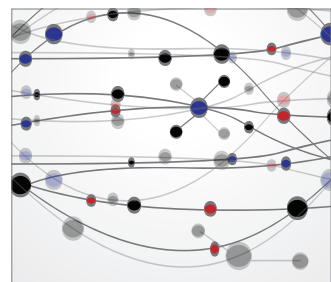

The Scientific World Journal
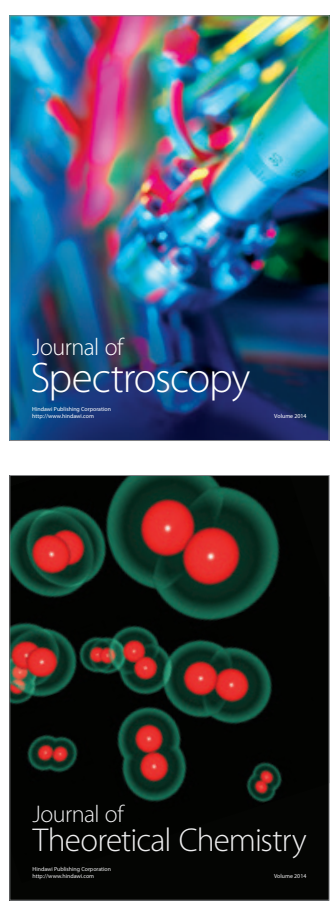
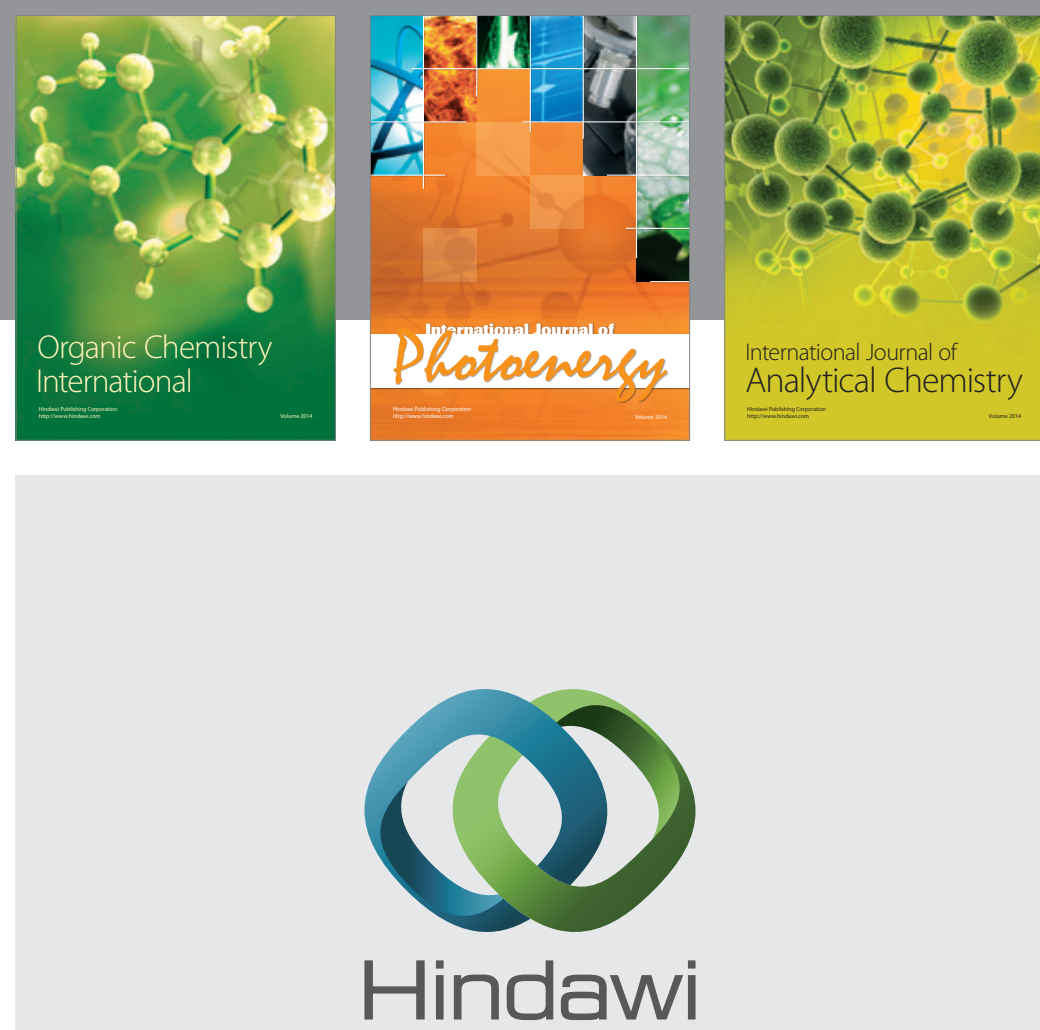

Submit your manuscripts at

http://www.hindawi.com
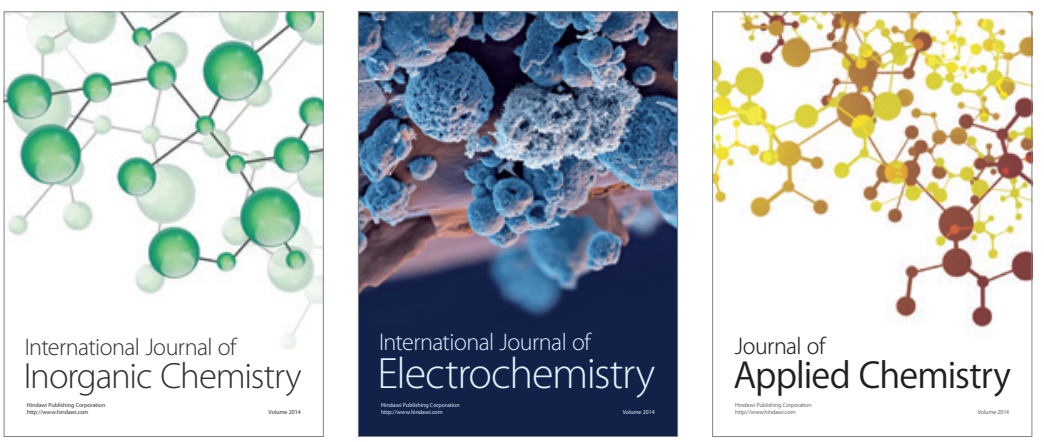

Journal of

Applied Chemistry
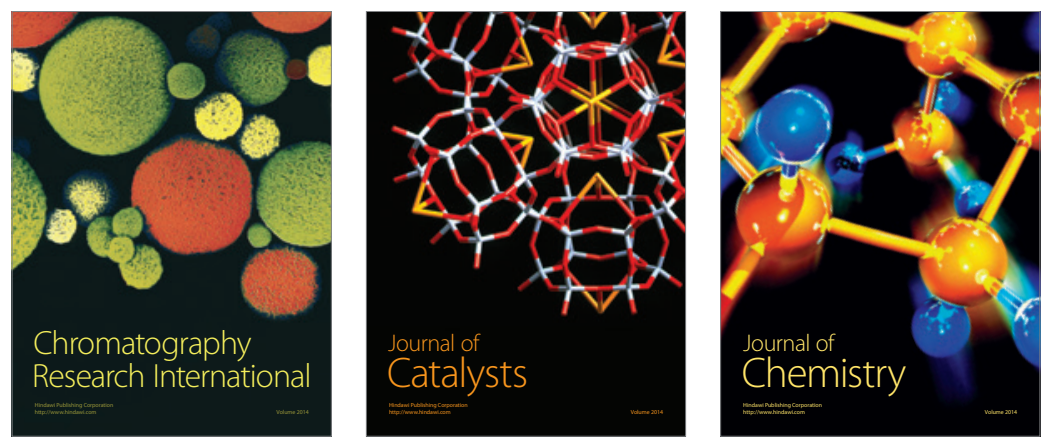
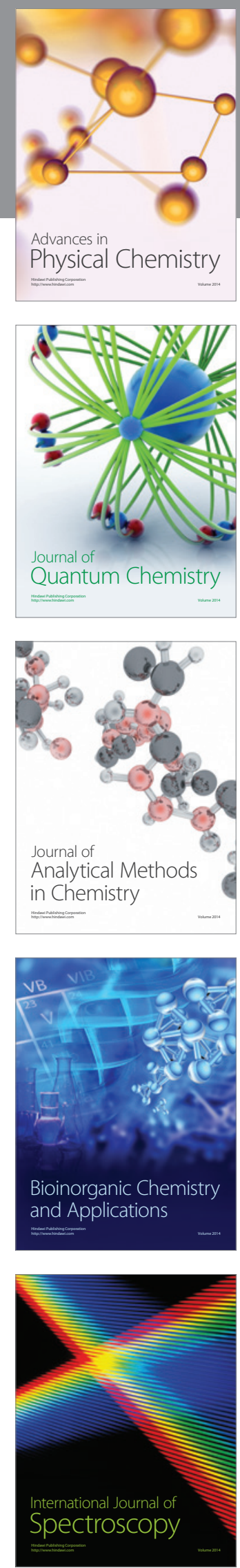